\section{AB0913 AGREEMENT STUDY AND EXPERT CONSENSUS FOR THE CLINICAL PICTURE OF CHIKV INFECTION}

J.C. Rueda ${ }^{1}$, J.-I. Angarita ${ }^{1}$, C. Pinzon ${ }^{2}$, A.M. Santos ${ }^{1}$, E.-L. Saldarriaga ${ }^{1}$, J.M. Rueda ${ }^{3}$, D.L. Saaibi ${ }^{4}$, E. Forero ${ }^{5}$, I. Pelaez-Ballestas ${ }^{6}$, P.X. Pavía ${ }^{7}$, J. Londono ${ }^{8}$. ${ }^{1}$ Reumatología; ${ }^{2}$ Departamento de Investigación Clínica, Facultad de Medicina, Universidad de la Sabana, Chia; ${ }^{3}$ Unidad de Reumatología, Centro Médico Imbanaco, Cali; ${ }^{4}$ Reumatología Ubit, Centro Médico Carlos Ardila Lulle, Bucaramanga; ${ }^{5}$ Medicina Interna, Reumatología, Universidad del Norte, Barranquilla, Colombia; ${ }^{6}$ Reumatología, Hospital General de México, México, Mexico; ${ }^{7}$ Unidad de Investigación Científica, Hospital Militar Central;

${ }^{8}$ Reumatología, Universidad de la Sabana-Hospital Militar Central, Bogotá, Colombia

Background: World Health Organization suggested case definitions to suspect and diagnose chikungunya virus infection which are: possible case, probable case and confirmed case. Although useful, when applied in practice, its lack definition for specific joint involvement and absence of other systemic symptoms apart from fever, leads to a broad clinical spectrum which increases the need for laboratory tests.

Objectives: To establish agreement on clinical criteria of CHIKV infection based on clinical expertise of specialists from affected areas of Colombia and to develop a set of clinical criteria.

Methods: A group of specialists in rheumatology, epidemiology and bacteriology from different parts of Colombia with experience in diagnosis and treatment of CHIKV patients from the epidemic of 2014-2015 met to reach agreements on clinical characteristics of CHIKV infection. A series of questions were formulated and agreement in percentage was calculated on the following answers: totally agree, agree, not in agree or disagree, disagree and totally disagree. Agreement was set when the sum to the answers totally agree and agree or disagree and totally disagree of was $\geq 50 \%$. When agreement was not reached, the moderator performed a discussion with the opinions of the confronting members of the group and after that reformulated the question. This procedure was made

Table 1. Agreement Percentage to Formulated Questions on CHIKV Clinical Characteristics Do you consider as clinical criteria: Totally Agree Not in Agree Disagree Totally Type of Agree or Disagree Disagree Agreement

\begin{tabular}{|c|c|c|c|c|c|c|}
\hline & & & & & & (Total) \\
\hline Symmetrical joint involvement & 100 & 0 & 0 & 0 & 0 & Agree (100) \\
\hline Abrupt onset of symptoms & 100 & 0 & 0 & 0 & 0 & Agree (100) \\
\hline Fever & 38 & 50 & 12 & 0 & 0 & Agree (78) \\
\hline Rash & 13 & 75 & 0 & 12 & 0 & Agree (88) \\
\hline Myalgia & 25 & 75 & 0 & 0 & 0 & Agree (100) \\
\hline Fatigue & 63 & 25 & 12 & 0 & 0 & Agree (88) \\
\hline Arthralgia in wrists & 50 & 25 & 13 & 0 & 12 & Agree (75) \\
\hline Arthritis in wrists & 75 & 13 & 0 & 12 & 0 & Agree (88) \\
\hline Arthralgia in hands & 88 & 12 & 0 & 0 & 0 & Agree $(100)$ \\
\hline Arthritis in hands & 88 & 12 & 0 & 0 & 0 & Agree (100) \\
\hline Arthralgia in knees & 13 & 63 & 0 & 12 & 12 & Agree (76) \\
\hline Arthritis in knees & 13 & 63 & 12 & 0 & 12 & Agree (76) \\
\hline Arthralgia in ankles & 100 & 0 & 0 & 0 & 0 & Agree $(100)$ \\
\hline Arthritis in ankles & 100 & 0 & 0 & 0 & 0 & Agree (100) \\
\hline Arthralgia in feet & 50 & 38 & 0 & 12 & 0 & Agree (88) \\
\hline Arthritis in feet & 75 & 13 & 0 & 12 & 0 & Agree (88) \\
\hline
\end{tabular}

Figure 1. Clinical Criteria

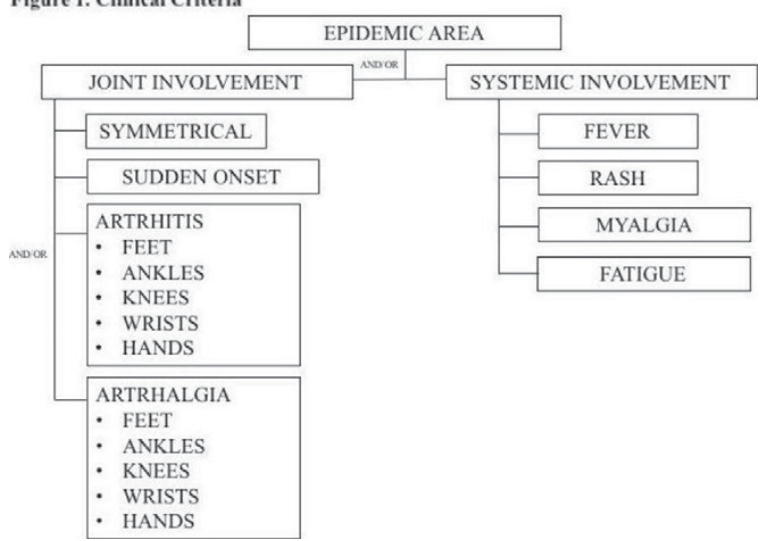

until agreement was reached. With the results a set of clinical criteria was proposed.

Results: The agreement percentage to the formulated questions are depicted in table 1. Disagreement was achieved with mucosal imvolvement (100\%), G/I involvement $(88 \%)$, and arthralgia and arthritis in shoulders (63\% and $100 \%)$ and in elbows (100\%).

Conclusions: Agreement was achieved in abrupt onset of symptoms, and the presence of fever, rash, myalgia, fatigue, and symmetrical arthritis or arthralgia of wrists, hands, knees, ankles and feet. A set of clinical criteria was proposed (figure 1).

Disclosure of Interest: None declared

DOI: 10.1136/annrheumdis-2017-eular.1882

\section{AB0914 CUTANEOUS LEISHMANIASIS IN PATIENTS TREATED WITH BIOLOGICAL THERAPY}

J. Lluch ${ }^{1}$, M. López de Recalde ${ }^{1}$, X. Michelena ${ }^{1}$, J. Marcoval ${ }^{2}$, X. Juanola ${ }^{1}$.

${ }^{1}$ Department of Rheumatology; ${ }^{2}$ Department of Dermatology, Hospital Universitari de Bellvitge, L'Hospitalet de Llobregat, Barcelona, Spain

Background: Leishmaniasis is a chronic protozoal disease endemic in several areas of the world. In the Mediterranean basin cutaneous leishmaniasis is caused by Leishmania infantum and usually produces localized skin lesions. Biological therapy (BT) may increase the risk of reactivation or development of infections such as tuberculosis, mycoses and protozoan diseases. However, there is scarce literature on Leishmania infections in patients treated with anti-TNF drugs. We have diagnosed five cases of cutaneous leishmaniasis in patients treated with anti-TNF drugs in the last four years.

Objectives: To show the clinical characteristics and the evolution of cutaneous leishmaniasis in patients treated with BT at a tertiary level hospital.

Methods: We reviewed the clinical characteristics, previous treatments, the complementary tests used for the diagnosis, the main disease, the therapy used for the treatment of the infection, the clinical evolution and the reintroduction of the BT.

Results: In the last four years we have diagnosed five cases of cutaneous leishmaniasis in patients treated with BT. Four of them were men and one a woman, the age range was 35 to 61 years old. In four of them the symptoms were only cutaneous, but one of them also had systemic impairment, basically hepatosplenomegaly. For the diagnosis skin biopsy, positive PCR for Leishmania DNA from skin samples, serology and response to treatment were all needed. Three cases were patients treated with adalimumab and two treated with infliximab. Three patients had Crohn's disease, one psoriatic arthritis and the other ankylosing spondylitis. The diagnostic delay was between 5 and 24 months. All patients were treated with EV liposomal amphotericin B, and two of them also received intralesional injections of meglumine antimoniate. In all cases resolution was achieved, and there have been no relapses to date after reintroduction of BT.

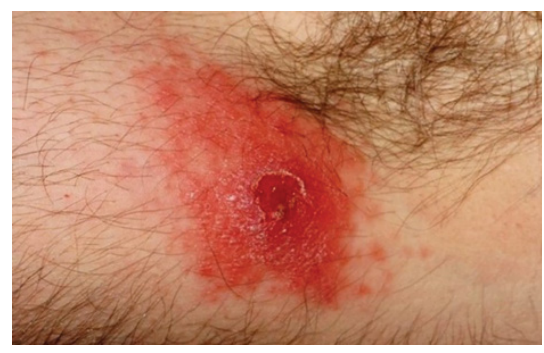

Conclusions: We have to consider cutaneous leishmaniasis in patients with BT who present compatible skin lesions, especially in endemic areas. It is important to be aware of this type of condition in order to make a fast and accurate diagnosis.

\section{References:}

[1] Alvar J, Vélez ID, Bern C, et al. WHO Leishmaniasis Control Team. Leishmaniasis worldwide and global estimates of its incidence. PLoS One 2012; 7:e35671.

[2] Dujardin JC, Campino L, Cañavate C et al. Spread of vector-borne diseases and neglect of Leishmaniasis, Europe. Emerg Infect Dis 2008; 14:1013-8.

Disclosure of Interest: None declared

DOI: 10.1136/annrheumdis-2017-eular.4259

Abstract AB0914 - Table 1

\begin{tabular}{|c|c|c|c|c|c|c|c|c|}
\hline Gender & Age & Disease & Biologic therapy & Time with BT & Affection & Evolution until diagnosis & Treatment & Evolution \\
\hline Man & 35 & Crohn disease & Adalimumab & 4 years & Cutaneous & 12 months & $\begin{array}{l}\text { Intralesional injections of meglumine antimoniate } \\
\text { EV liposomal amphotericin B. }\end{array}$ & $\begin{array}{l}\text { Resolution. } \\
\text { Reintroduction of BT. }\end{array}$ \\
\hline Woman & 55 & Crohn disease & Infliximab & 3 years & Cutaneous & 24 months & $\begin{array}{l}\text { Intralesional injections of meglumine antimoniate } \\
\text { EV liposomal amphotericin B. }\end{array}$ & $\begin{array}{l}\text { Resolution. } \\
\text { Reintroduction of BT. }\end{array}$ \\
\hline Man & 61 & Crohn disease & Adalimumab & 3 years & $\begin{array}{l}\text { Cutaneous and } \\
\text { hepatosplenomegaly }\end{array}$ & 5 months & EV liposomal amphotericin B & $\begin{array}{l}\text { Resolution. } \\
\text { Reintroduction of BT. }\end{array}$ \\
\hline Man & 58 & Psoriatic arthritis & Adalimumab & 19 months & Cutaneous & 8 months & EV liposomal amphotericin B & Resolution. \\
\hline Man & 51 & Ankylosing spondylitis & Infliximab & 12 years & Cutaneous & 5 months & EV liposomal amphotericin B & $\begin{array}{l}\text { Resolution. } \\
\text { Reintroduction of BT. }\end{array}$ \\
\hline
\end{tabular}

